\title{
Estimación cuantitativa y cálculo de emisiones ambientales (huella de carbono), en el terminal terrestre de la ciudad de Guaranda.
}

\section{Quantitative estimation and calculation of environmental emissions (carbon footprint), in the land terminal of the city of Guaranda.}

Manolo Alexander Córdova Suárez. ${ }^{1}$, Christian Patricio Medina Cunalata. ${ }^{2}$ Oscar Eduardo Ruíz Robalino. ${ }^{3}$, José Geovanny Vega Pérez. ${ }^{4}$, Julio Cesar Sosa Cárdenas ${ }^{5}$ \& Edwin Leonardo Sánchez Almeida ${ }^{6}$

Recibido: 19-06-2017 / Revisado: 25-08-2017 Aceptado: 18-09-2018/ Publicado: 01-10-2018

\begin{abstract}
.
DOI: https://doi.org/10.33262/cienciadigital.v2i4.229

The air pollution has been affected by the emission of GHG greenhouse gases as methane, carbon dioxide among others that are responsible for climate change, some by natural causes and other anthropogenic. (Díaz Cordero, 2012). Issued emissions to the atmosphere of carbon dioxide is the most important gas of greenhouse effect gases, anthropogenic emissions generated by burning fossil fuels processes represent $75 \%$ of the emissions, generated by the consumption of energy and the transport sector. (Pizzinato, 2009) Among the main causes generated by climate change on the health of the people, this possible modification in the transmission of infectious diseases, and fast routes of infection through viruses, bacteria and other microorganisms. (Corvalán, 2003).

Methods: the development of the methodology is summarized into three parts for the estimation of carbon footprint, the first by the classification of the bus fleet by the standard EURO in order to categorize and demonstrate the technology that most influences the emission of gases, second measurement of greenhouse gases through the use of team ECA Bacharach 450 through a tube

\footnotetext{
1 G+ Energy-Risks \& Engineering Group, Department of Food Science and Engineering, Technical University of Ambato, Ambato-Ecuador, ma.cordova@uta.edu.ec

2 Department of Food Science and Engineering, Technical University of Ambato, Ambato-Ecuador, cmedina9495@uta.edu.ec

3 G+ Energy-Risks \& Engineering Group, Department of Food Science and Engineering, Technical University of Ambato, Ambato-Ecuador, oe.ruiz@uta.edu.ec

4 G+ Energy-Risks \& Engineering Group, Department of Food Science and Engineering, Technical University of Ambato, Ambato-Ecuador, jg.vega@uta.edu.ec

5 Department of Food Science and Engineering, Technical University of Ambato, Ambato-Ecuador, jc.sosa@uta.edu.ec

6 Indoamerica Technologic University, Ambato, Ambato-Ecuador, leonardosanchez@uti.edu.ec
} 
that has the team, direct measurement at the source of emission tube exhaust, and third party assessment of the results of the agreement to the international standards any ISO 14064 and GHG protocol.

Results: we performed direct measurement at the source of the 267 buses that were subject of study, classified by technology EURO for the identification of the main contributor of carbon footprint, with EURO II technology unit that more emissions of greenhouse gases contribute to climate change.

Conclusion: was the quantitative estimate of the carbon footprint of the Bus Terminal of the city of Guaranda by issuing a total of 31990,21 t CO2e per year value that corresponds to the source of emission of the fleet of bus exhaust pipes almost in its entirety, you use to meet functions of transport service.

Keywords: Footprint carbon, greenhouse gases, Euro standard.

\section{Resumen.}

La contaminación del aire se ha visto afectada por la emisión de gases de efecto invernadero, gases como el metano, dióxido de carbono entre otros que son los responsables de los cambios climáticos, algunos por causas naturales y otras de origen antropogénico. (Díaz Cordero, 2012).

De las emisiones emitidas al ambiente el dióxido de carbono es el gas más importante de los gases de efecto invernadero, las emisiones antropogénicas generadas por procesos de quema de combustibles fósiles representan el $75 \%$ de las emisiones, generadas por el consumo de energía y por el sector del transporte. (Pizzinato, 2009)

Entre las principales causas generadas por el cambio climático en la salud de las personas, está la posible modificación en la transmisión de enfermedades infecciosas, y rápidas vías de contagio a través de virus, bacterias y otros microorganismos. (Corvalán, 2003)

Métodos: el desarrollo de la metodología se resume en tres partes para la estimación de la huella de carbono, la primera mediante la clasificación de la flota de autobuses por la norma EURO con el fin de categorizar y evidenciar la tecnología que más influye en la emisión de gases, segundo la medición de gases de efecto invernadero mediante el uso del equipo Bacharach ECA 450 a través de una sonda que dispone el equipo, medición directa en la fuente de emisión el tubo de escape, y tercero la valoración de los resultados de acuerdo a la normas internacionales ISO 14064 y GHG protocol.

Resultados: se realizó la medición directa en la fuente de 267 buses que fueron objeto de estudio, clasificados por tecnología EURO para la identificación del principal contribuyente de la Huella de Carbono, siendo EURO II la tecnología por unidad que más emisiones de gases de efecto invernadero contribuye al cambio climático.

Conclusión: se realizó la estimación cuantitativa de la Huella de carbono del Terminal Terrestre de la ciudad de Guaranda emitiendo un total de 31990,21 t $\mathrm{CO}_{2}$-e, al año, valor que casi en su 
totalidad, corresponde a la fuente de emisión de los tubos de escape de la flota de autobuses que cumplen funciones de servicio de transporte.

Palabras Claves: Huella de carbono, gases de efecto invernadero, Tecnología Euro.

\section{Introducción.}

Los problemas ambientales de hoy en día como el calentamiento global, las lluvias ácidas y las elevadas temperaturas; son complicaciones que ha venido sufriendo el planeta Tierra, causadas principales por el empleo de fuentes energéticas de origen fósil y su consecutiva generación de gases de efecto invernadero que contribuyen al cambio climático. La generación de gases como el anhídrido carbónico, óxidos de nitrógeno y metano son parte de los principales colaboradores para la generación de la Huella de Carbono. (Amestoy Alonso, 2010).

El cambio climático es un problema que a través de los años ha superado la incidencia de solo áreas locales convirtiéndose en un problema global provocando la perdida de la biodiversidad y reducción del ozono, se resume como una problemática de tipo exponencial, lo que significa una duplicación de su variable en tiempos cada vez más cortos, además trata de un hecho persistente, dado que se mantendrá por un tiempo largo debido a la residencia de los químicos contaminantes en el medio ambiente, inclusive cortando el problema de raíz. (Velazquez de Castro Gonzalez, 2005).

La huella de carbono se ha convertido en una herramienta muy importante para la cuantificación de gases de efecto invernadero, la misma que representa cierta cantidad de emisiones ambientales relevantes para el cambio de clima, generados por actividades de consumo y de producción por el hombre, se expresa en toneladas de CO2e. (Wiedmann Minx, 2008)

La contaminación del aire ha generado una preocupación a nivel mundial por su incidencia en el medio ambiente y ser el causante de enfermedades graves en la salud de las personas, contribuyendo también a problemas económicos en zonas urbanas, problema generado por el incremento acelerado de la población vehicular y por los procesos de combustión incompleta que desarrolla los motores de los vehículos. (Mathew \& Bombay, 2014). Siendo las emisiones de tráfico vehicular el foco emisor de gases de efecto invernadero como son las emisiones a través de los tubos de escape, emisiones evaporativas y emisiones por abrasión. (Vega, Ocaña, Parra, 2012).

Este trabajo tuvo como objetivo la estimación cuantitativa y cálculo de la Huella de Carbono en el Terminal Terrestre de Guaranda.

\section{Materiales y método.}

El desarrollo de la presente investigación se realizó en base a la metodología de las normas ISO 140064 que contiene los parámetros de evaluación y GHG Protocol como herramienta de cálculo de la Huella de carbono.

\section{Toma de muestras}


El estudio de gases de efecto invernadero es un trabajo de exposición directa en la fuente emisora por lo que es necesario de equipos de protección personal para el muestreo.

Se realizó una categorización de los autobuses de acuerdo a su año de fabricación mismos que desempeñan sus actividades de servicio de transporte en el Terminal Terrestre de la ciudad de Guaranda, basándose en la tecnología Euro, norma que regula el nivel mínimo de emisiones de gases que dependen de la homologación y leyes ambientales de cada país, para Ecuador la normativa vigente de aplicación es la tecnología Euro III con calidad de combustible tipo II, teniendo una relación directa la tecnología Euro con la calidad del combustible. (Asociación de empresas automotrices del Ecuador, 2016).

\section{Medición de gases de efecto invernadero}

La evaluación de Gases de Efecto Invernadero requiere del uso de tecnologías certificadas que garanticen un estudio real de las mediciones de la huella de carbono por tal motivo, la verificación de analizadores de medición que ha detallado Environmental Technology Agency, permite el uso del equipo BACHARACH ECA 450 como analizador certificado para la medición de gases de efecto invernadero por su tecnología de celdas electroquímicas y microprocesadores que dispone el equipo. (EPA / ETV, 2009)

La metodología para la medición se realizó en base a la gestión ambiental de la norma técnica Ecuatoriana obligatoria para la determinación de concentraciones de emisiones ambientales emitidas por los tubos de escape de los automotores, en base al régimen de giro mínimo que genera el automotor conocido como ralentí o condición mínima de marcha, (NTE INEN 2207, 2016), mediciones realizadas directamente en la fuente de emisión de los autobuses atreves de la sonda que dispone el equipo BACHARACH ECA 450.

\section{Normas de aplicación para el desarrollo del estudio.}

Desarrollado la medición de los gases en la fuente de emisión se procesó los datos de acuerdo a estándares base para la elaboración de inventarios de gases de efecto invernadero que presenta la norma ISO 14064 siendo una guía metodológica de evaluación de las emisiones ambientales de acuerdo a las definiciones y requisitos que describe la norma por el tipo de emisión generado (Norma UNE-ISO 14064:2006, 2012), y la norma GHG protocol como herramienta para el proceso de cálculo de la huella total de carbono, en base al consumo de combustible diario de los autobuses en litros al día, siendo una metodología directamente relacionada con la cantidad de emisiones de gases generados . (GREEN HOUSE GAS PROTOCOL, 2013).

\section{Metodología de aplicación de la norma ISO 14064}

La guía metodológica de la norma ISO 14064 describe una serie de parámetros adaptados a la necesidad de obtener la estimación de la Huella de carbono en las instalaciones del terminal terrestre, mediante la clasificación por el tipo de emisión siendo las emisiones directas, indirectas y otras emisiones indirectas.

\section{Identificación de emisiones directas de Gases de efecto invernadero.}

Son todas las emisiones producidas por el desarrollo de actividades propias del establecimiento, provenientes de fuentes de emisión que son controladas por el Terminal Terrestre de Guaranda. 


\section{Identificación de emisiones indirectas de Gases de efecto invernadero}

Pertenece a las emisiones provenientes por el consumo de electricidad que genera el establecimiento, alcance evaluado de acuerdo a las planillas de consumo energético expresado en $\mathrm{KW} / \mathrm{H}$.

\section{Identificación de otras emisiones indirectas de Gases de efecto invernadero.}

Son todas las emisiones que no dependen de las actividades propias del establecimiento es decir no están controladas, perteneciente a los autobuses que utilizan el Terminal como zona de embarque de usuarios.

\section{Metodología para la cuantificación de emisiones de acuerdo a la GHG Protocol.}

\section{Emisiones directas de Gases de efecto invernadero y otras emisiones indirectas}

Para la aplicación de GHG protocol como herramienta de cálculo para las emisiones directas y otras emisiones indirectas es necesario el dato de actividad, calculados mediante el consumo de combustible diario de los vehículos y el factor de emisión de los gases de efecto invernadero (metano, dióxido de carbono, Dióxido de nitrógeno). (GREEN HOUSE GAS PROTOCOL, 2013)

\section{Emisiones indirectas de Gases de efecto invernadero.}

Las emisiones indirectas se evaluaron de acuerdo al consumo de electricidad de acuerdo a las planillas durante un año atrás del estudio, calculado por el producto de la energía consumida en (MWh) y el factor de emisión eléctrico, que para Ecuador es 0,5062 $\mathrm{tCO}_{2 /} \mathrm{MWh}$.

\section{Resultados.}

\section{Clasificación de la flota vehicular}

De acuerdo a la modificatoria 3 del reglamento técnico RTE INEN 028 del uso de combustibles acorde a las políticas ambientales del Gobierno Ecuatoriano exige el cumplimiento para el tránsito vehicular la aplicación de la tecnología EURO III y la producción de combustibles que cumpla los requisitos que exige la norma EURO. (INEN, 2017)

Tabla. 1 Clasificación de la flota vehicular por la tecnología EURO.

\begin{tabular}{cccc}
\hline Tecnología & Rango & Muestra & $\begin{array}{c}\text { Población } \\
\text { total }\end{array}$ \\
\hline EURO I & $1994-2000$ & 0 & 0 \\
EURO II & $2001-2010$ & 66 & 110 \\
EURO III & 2011 en adelante & 201 & 335 \\
\hline TOTAL & - & 267 & 445 \\
\hline
\end{tabular}

Nota: Adaptado de (INEN, 2017)

La flota de autobuses fue categorizada por el año de fabricación, EURO I no presenta unidades en circulación, debido a las normas y legislaciones que exigen la renovación de las unidades en tránsito (Ley orgánica de transporte terrestre , 2014), del total de autobuses el $25 \%$ corresponde a EURO II 
que han cumplido la resolución $\mathrm{N}^{\circ}$ 080-DIR-2010-CNTTSV que estipula el tiempo de vida máximo para la circulación vehicular para buses interprovinciales es de 20 años (Comisión de transito del Ecuador, 2010), la tecnología EURO III dispone de 335 autobuses pertenecientes al $75 \%$ de las unidades las mismas que han cumplido el proceso de modernización vehicular con el objetivo de brindar un servicio de calidad y buscar la satisfacción del cliente reduciendo las emisiones ambientales por la aplicación de nuevas tecnologías. (Laureano, Garza, Mar, 2012)

\section{Reporte de emisiones de gases de efecto invernadero.}

Para el reporte de resultados de las emisiones se categorizó las fuentes de emisión de acuerdo a los alcances o tipos de emisiones, descritas en la Tabla. 2, sin tener actividad contribuyente al cálculo de las emisiones directas por la ausencia de vehículos propias del establecimiento.

Tabla. 2 Alcances de la Huella de Carbono.

\begin{tabular}{ccc}
\hline Alcance & Tipo de emisión & Descripción \\
\hline Alcance I & Emisiones directas. & No dispone de vehículos propios. \\
Alcance II & Emisiones indirectas. & 1 medidor \\
& & \\
Alcance III & Otras emisiones indirectas. & 445 autobuses. \\
\hline
\end{tabular}

\section{Comparación de los gases de efecto invernadero influyentes en la Huella de Carbono.}

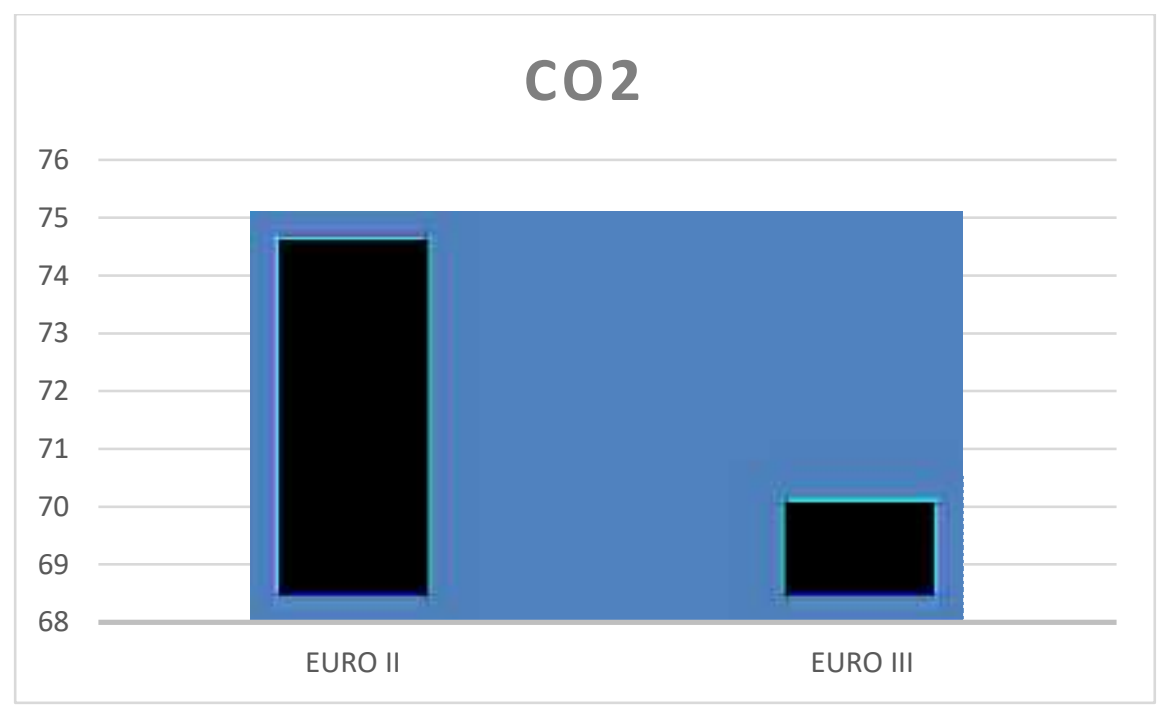

Figura. 1 Comparación de emisiones de $\mathrm{CO}_{2}$ por tecnología EURO.

Entre las fuentes de emisión más importantes para la generación de gases está el consumo de combustibles como la gasolina y diésel que desprenden $\mathrm{CO}_{2}$ por procesos de combustión o quema de los combustibles fósiles. (Distrito Metropolitano de Quito, 2013). La evaluación realizada de acuerdo a la tecnología EURO mostró como contribuyente principal para la generación de dióxido de carbono 
a la tecnología EURO II con un aporte de 75.10 toneladas de $\mathrm{CO}_{2}$ e por unidad y a EURO III con un total de emisión de 70.54 toneladas de $\mathrm{CO}_{2}$ e por unidad.

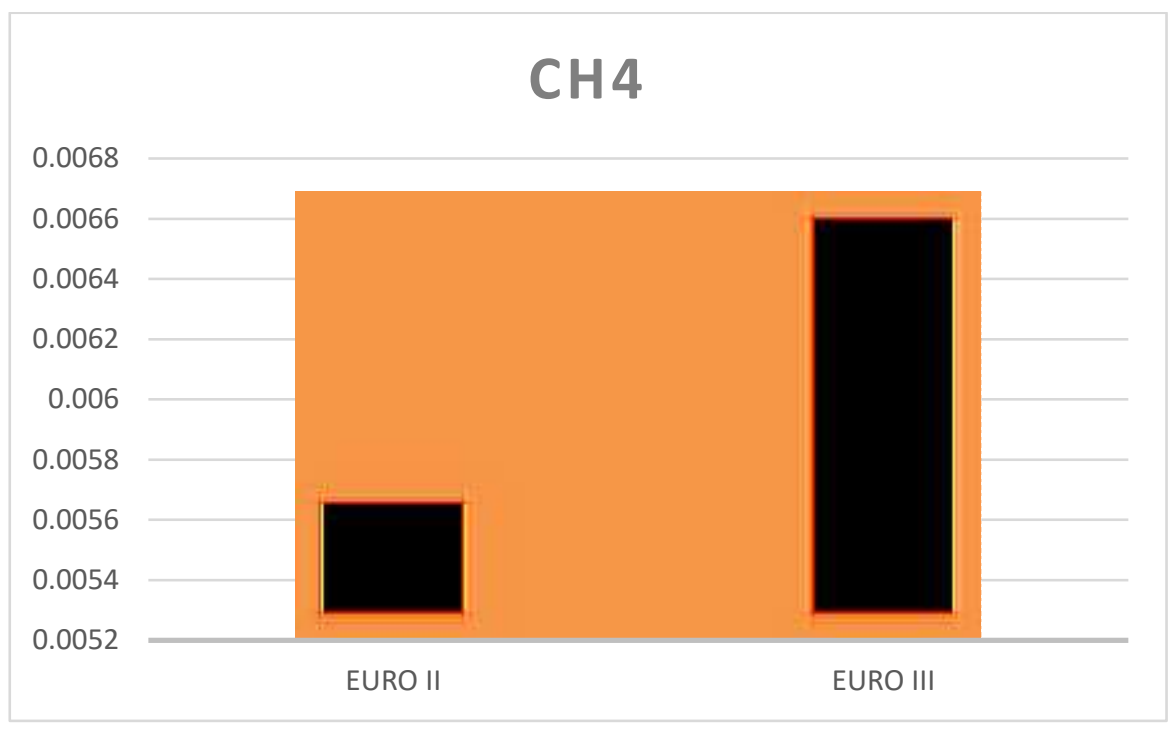

Figura. 2 Comparación de emisiones de $\mathrm{CH} 4$ por tecnología EURO.

En los procesos de quema de combustibles en los tubos de escape se genera grandes cantidades de $\mathrm{CO} 2$ en vehículos de gasolina, sin embargo, a pesar que los vehículos a diésel muestren un ahorro de carburante y la emisión de dióxido de carbono sea menor la presencia de sustancias orgánicas como el metano se hacen presentes. (Greenpeace, 2009), la generación de metano depende de la tecnología EURO presentando mayor cantidad de emisiones EURO III con $0.0066_{\mathrm{t}} \mathrm{CH}_{4}$ mientras que EURO II generó $0.0057 \mathrm{t}_{\mathrm{CH}}$, siendo considerado un gas influyente en el efecto invernadero por su elevado potencial de calentamiento responsable del calentamiento global. (Global Methane Initiative, 2011)

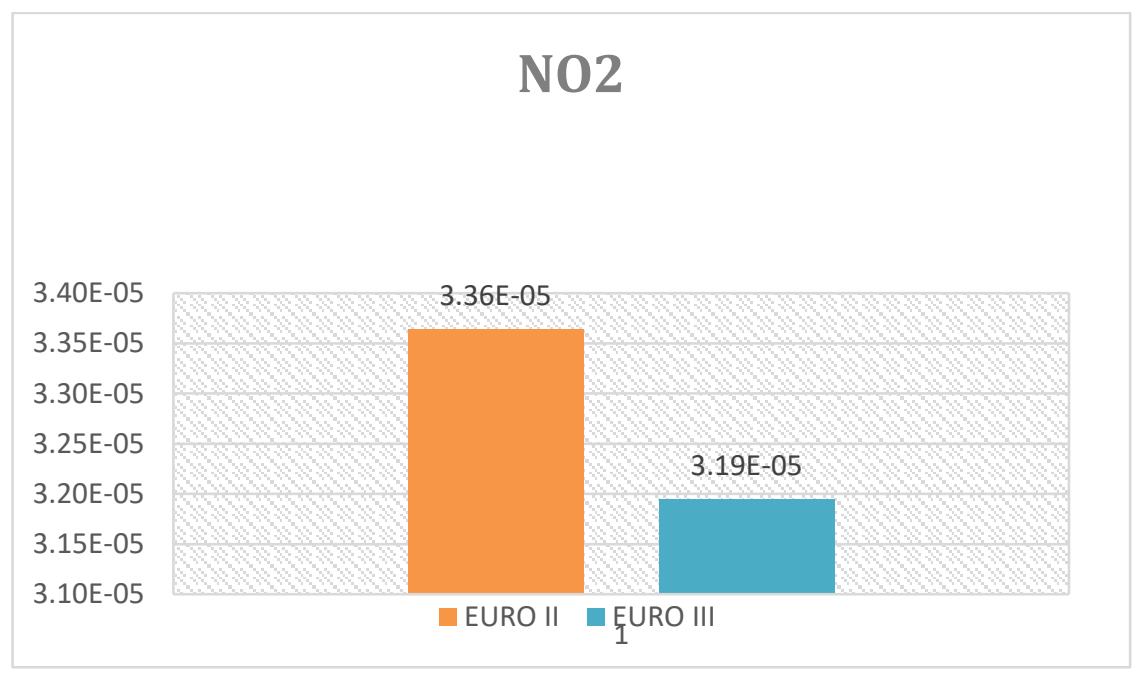

Figura. 3. Comparación de emisiones de $\mathrm{NO}_{2}$ por tecnología EURO. 
Entre otro de los gases evaluados para la Huella de Carbono está el óxido nitroso, gas influyente en el calentamiento del planeta por su elevado potencial de calentamiento, generado en procesos de quema de combustibles de diésel a elevadas temperaturas. (Jorge herrera), presentan un valor bajo de emisión al medio ambiente sin existir diferencias significativas entre las tecnologías EURO presentando valores aceptables dentro de los límites permisibles de regulación de acuerdo a la norma de calidad del aire ambiente que establece como límite máximo de concentración al año de 0.04 $\mathrm{mg} / \mathrm{m} 3$. (Comisión especial de estadistica ambiental, 2016)

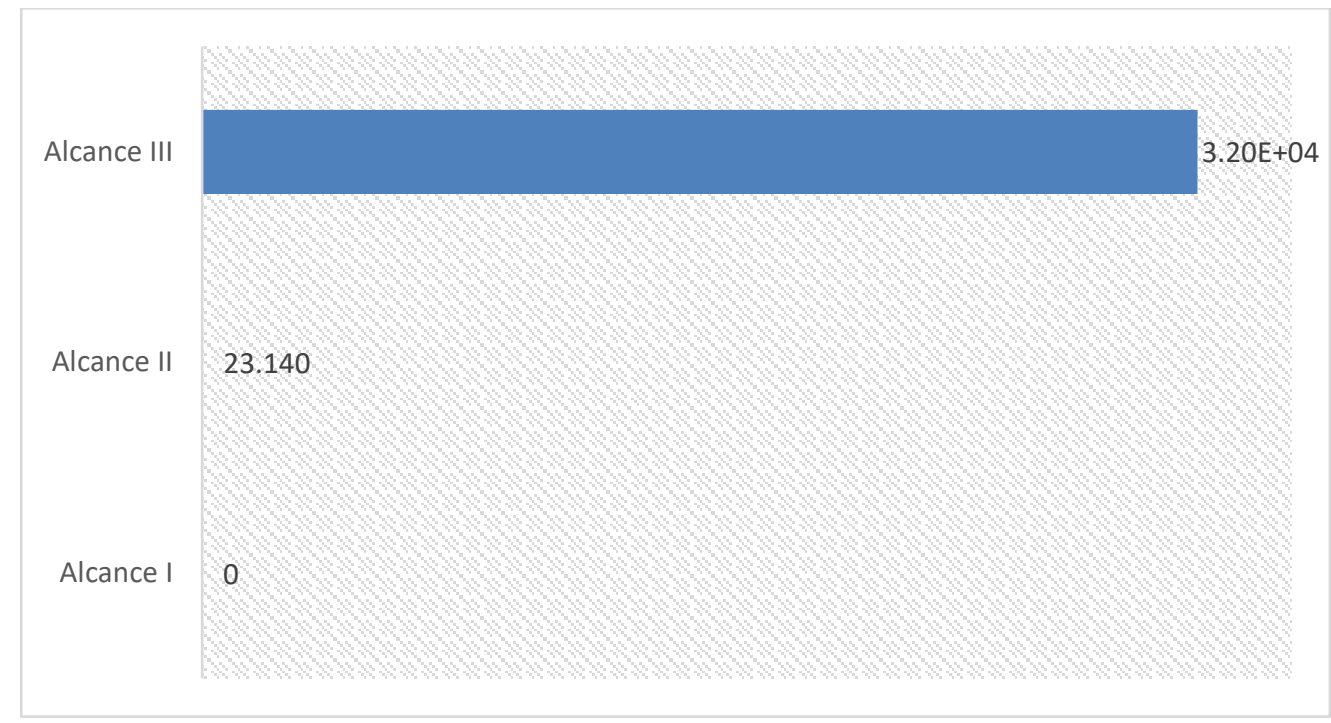

Figura 4. Reporte de la Huella de carbono por fuente de emisión.

\section{Discusión.}

La evaluación de gases de efecto invernadero, es una medida para estimar el grado de contaminación proveniente de distintas fuentes de emisión evaluadas a través de la Huella de carbono, la estimación cuantitativa se valoró de acuerdo a los alcances o fuente de origen de emisión, en la que el principal generador de la Huella de carbono con un $99.99 \%$ de incidencia es la flota de autobuses que realizan sus actividades operativas dentro del terminal, siendo la tecnología EURO la responsable del nivel de emisión, en la que EURO II presenta mayor nivel de gases de efecto invernadero, que la tecnología EURO III. La contribución de del $0.01 \%$ a la Huella de Carbono en el terminal terrestre pertenece el consumo eléctrico que emite un total de 23.140 t $\mathrm{CO}_{2}$-e al año, las emisiones directas relacionas a vehículos propios de la institución no fueron tomadas en cuenta dado la ausencia del automotor, debido a que el área del terminal está centralizada y no requiere el uso propio de un vehículo. Se reportó un valor total de la huella de carbono del Terminal terrestre de la ciudad de Guaranda de 31990,21 t $\mathrm{CO}_{2 \mathrm{e}}$ comprendidas en las tres fuentes de emisión.

\section{Conclusiones.}

- Las mediciones de los gases se evaluaron a través del Equipo Bacharach 450, mediante su tecnología de celdas electroquímicas y microprocesadores especializados, valorando los gases de efecto invernadero en la fuente directa de emisión de los tubos de escape de los vehículos. 
- El desarrollo de inventarios de gases de efecto invernadero en referencia a las normas internacionales permitió la estimación cuantitativa de la Huella de Carbono generada por las actividades del Terminal terrestre de Guaranda; analizado de acuerdo al tipo de emisiones emitidas, donde las actividades que no son controladas por el Terminal resultaron ser las más influyentes para la emisiones ambientales con un total del 99.99\% perteneciente a otras emisiones indirectas generando $31967.18 \mathrm{t} \mathrm{CO}_{2 \mathrm{e}}$ provocadas por los autobuses que transitan en el establecimiento.

- La categorización de la flota vehicular permitió la identificación de la tecnología Euro con mayor incidencia en la generación de gases de efecto invernadero y contribución a la huella de carbono, siendo el principal contaminante la tecnología EURO II con 75.3 t $\mathrm{CO}_{2 \mathrm{e}}$ por unidad mientras que EURO III en promedio emite $70.7 \mathrm{t} \mathrm{CO} 2 \mathrm{e}$, , siendo la principal causa de contaminación la falta de modernización de los autobuses, la falta de mantenimiento y la calidad de combustible para la acumulación de emisiones en el ambiente.

\section{Referencias Bibliográficas.}

Amestoy Alonso, J. (2010). El planeta Tierra en peligro (Calentamiento Global, Cambio Climático. Soluciónes). España: Editorial Club Universitario.

Asociación de empresas automotrices del Ecuador. (2016). Informa de calidad de combustibles petrocomercial, Periodicos en América Latina. AEADE, 33-34. Obtenido de http://www.aeade.net/anuario-2016/anuario2016.pdf

Comisión de transito del Ecuador. (2010). Cuadro de vida útil para los vehículos de transportación pública. 1-5.

Comisión especial de estadistica ambiental. (2016). Homologación del cálculo del indicador de concentración promedio anual del dióxido de nitrogeno (NO2) en el aire. INEC, 1-2.

Corvalán, C. (2003). Cambio climático y salud humana - Riesgos y respuestas. Catalogación por la Biblioteca de la OMS, 16-17.

Díaz Cordero, G. (2012). El cambio climático. Ciencia y Sociedad, 227-240. Obtenido de http://www.redalyc.org/pdf/870/87024179004.pdf

Distrito Metropolitano de Quito. (2013). Evaluación de la Huella de Carbono y Huella Hídrica Distrito metropolitano de Quito. Huella de Ciudades, 34-38.

EPA / ETV. (2009). Greenhouse Gas Monitoring Technologies. Tech brief environmenal technology verification program, file:///C:/Users/hpcorei7/Downloads/EPA-Greenhouse-gases.pdf .... / https://archive.epa.gov/nrmrl/archive-etv/web/pdf/01_vr_bach.pdf. 
Global Methane Initiative. (2011). Metano de los sistemas de petróleo y gas: Reducción de las emisiones, avance de la recuperacióny utilización. Iniciativa global del metano, 1-2.

GREEN HOUSE GAS PROTOCOL. (2013). Technical guidance for calculating scope 3 emissions (versión Carbon Trust, http://ghgprotocol.org/sites/default/files/standards/Scope3_Calculation_Guidance_0.pdf.

Greenpeace. (2009). Transporte: el motor del cambio climático. Greenpece.es, 26-27.

INEN. (2017). REGLAMENTO TÉCNICO ECUATORIANO RTE INEN 028 (1R) "COMBUSTIBLES". Servicio Ecuatoriano de Normalizción, http://www.pudeleco.com/files/a17027h.pdf.

Laureano, Garza, Mar, O. (2012). Implementación de un sistema de gestión eficiente de flotas de transporte para la sostenibilidad económica en una empresa de transporte. 3-6.

Ley orgánica de transporte terrestre . (2014). Ley orgánica de transporte terrestre transito y seguridad vial. Lexis, 26-27, 57-58. Obtenido de https://www.turismo.gob.ec/wpcontent/uploads/2016/04/LEY-ORGANICA-DE-TRANSPORTE-TERRESTRETRANSITO-Y-SEGURIDAD-VIAL.pdf

Mathew, T. V., \& Bombay, I. (2014). Fuel Consumption and Emission. Obtenido de http://nptel.ac.in/courses/105101008/downloads/cete_43.pdf

Norma UNE-ISO 14064:2006. (2012). Guía metodológica para la aplicación de la Norma UNE-ISO 14064-1: 2006 para el desarollo de inventarios de Gases de efecto invernadero en organizaciones.

Ihobe, http://www.euskadi.eus/contenidos/documentacion/uneiso14064/es_def/adjuntos/PUB2012-019-f-C-001.pdf.

NTE INEN 2207. (2016). GESTIÓN AMBIENTAL. AIRE. VEHÍCULOS AUTOMOTORES LÍMITES PERMITIDOS DE EMISIONES PRODUCIDAS POR FUENTES MOVILES TERRESTRES QUE UTILIZAN DIESEL. NormaTécnica Ecuatorina Obligatoria, 1-4.

Pizzinato, S. (2009). Transporte: El motor del cambio climático. Greenpeace, 25-27.

Vega, Ocaña, Parra, D. (2012). Inventario de emisiones atmosféricas del tráfico vehicular en el Distrito Metropolitano de Quito. Avances en ciencias e Ingenierias, 86-94.

Velazquez de Castro Gonzalez, F. (2005). Cambio climático y protocolo de kioto ciencia y estrategias. Revista Española de Salud Pública, 191-201.

Wiedmann Minx, T. J. (2008). A definition of "Carbon Foortprint". Research \& Consulting, 1-11. 


\section{Para citar el artículo indexado.}

Córdova M., Medina Ch., Ruíz O., Vega J., Sosa J. \& Sánchez E., (2018) Estimación cuantitativa y cálculo de emisiones ambientales (huella de carbono), en el terminal terrestre de la ciudad de Guaranda. Revista electrónica Ciencia Digital 2(3), 283-293. Recuperado desde:

http://cienciadigital.org/revistacienciadigital2/index.php/CienciaDigital/article/view/229/34 1

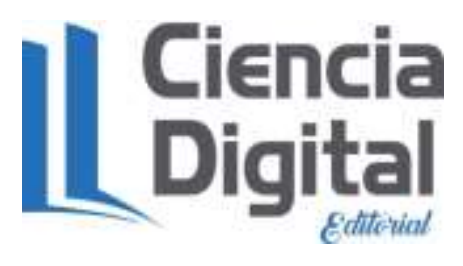

El artículo que se publica es de exclusiva responsabilidad de los autores y no necesariamente reflejan el pensamiento de la Revista Ciencia Digital.

El articulo queda en propiedad de la revista y, por tanto, su publicación parcial y/o total en otro medio tiene que ser autorizado por el director de la Revista Ciencia Digital.
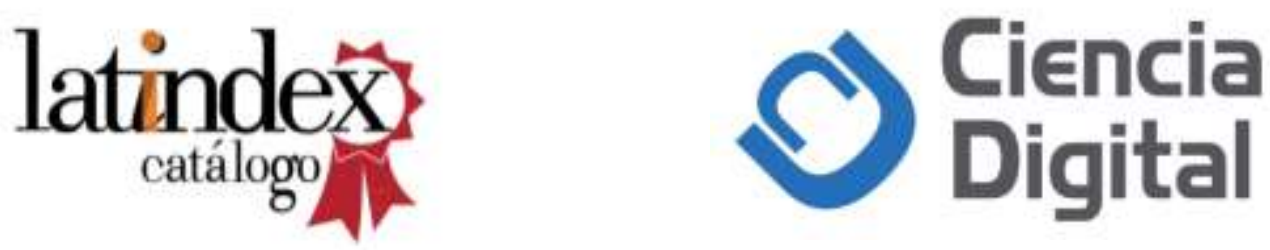